\title{
Born in winter or spring more susceptible to all-cause and cardiovascular disease death in rural areas of China: results from a 11.9-year follow-up study
}

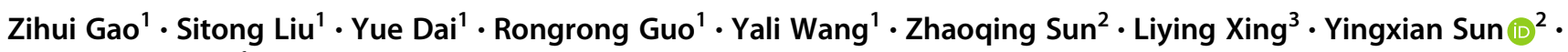 \\ Liqiang Zheng $\mathbb{1}^{1}$
}

Received: 23 July 2020 / Revised: 30 September 2020 / Accepted: 7 October 2020 / Published online: 27 January 2021

(c) The Author(s), under exclusive licence to Springer Nature Limited 2021

\begin{abstract}
There has been no evidence on the effects of birth season and birth month on mortality in China. We aimed to explore the association between birth season, birth month and all-cause and cardiovascular disease (CVD) death. A population-based sample of 21,338 Chinese rural participants aged $\geq 35$ years at baseline was included in our analysis. Age and multivariable adjusted Cox proportional hazards models were used to estimate hazard ratios (HRs) and 95\% confidence intervals (95\% CIs) for the relationship between astronomical birth season (autumn as the reference), birth month (November as the reference), and all-cause and CVD mortality. During a median follow-up period of 11.9 years, 2,207 people died from allcause and 1,214 people were attributed to CVD death. In multivariable adjusted analyses, for all-cause death, spring and winter had HRs (95\% CIs) of 1.134 (1.005-1.280) and 1.162 (1.038-1.301), respectively; January, March, May, and August had HRs (95\% CIs) of 1.249 (1.027-1.518), 1.234 (1.008-1.512), 1.276 (1.037-1.571), and 1.232 (1.003-1.513), respectively. For CVD death, spring and winter with HRs (95\% CIs) of mortality were $1.232(1.048-1.449)$ and 1.174 (1.007-1.369), respectively; March with HR (95\% CI) of mortality were $1.343(1.030-1.750)$ (all $P<0.05)$. Our study indicated that people born in the winter or spring were significantly associated with all-cause and cardiovascular disease mortality in rural areas of China.
\end{abstract}

These authors contributed equally: Zihui Gao, Sitong Liu

Supplementary information The online version of this article (https:// doi.org/10.1038/s41371-020-00432-0) contains supplementary material, which is available to authorized users.

Yingxian Sun

sunyingxian12@126.com

$\triangle$ Liqiang Zheng

liqiangzheng@126.com

1 Department of Cardiology, Department of Library and Department of Clinical Epidemiology, Shengjing Hospital of China Medical University, Shenyang 110004, PR China

2 Department of Cardiology, Shengjing Hospital of China Medical University, Shenyang 110004, PR China

3 Institute of Chronic Disease, Liaoning Provincial Center for Disease Control and Prevention, Shenyang 110005, PR China

\section{Introduction}

The 2019 novel coronavirus, later named COVID-19 by the World Health Organization, is a newly emerged humaninfectious coronavirus [1]. So far, COVID-19 have been raging all over the world, and new confirmed cases have appeared abroad. In the context of the nationwide and worldwide resistance to the epidemic, we have to consider the impact of the surrounding environment, including climate, temperature, humidity, on humans. As we all know, the occurrence and spread of many infectious diseases are affected by the season to some extent. However, there is a relative scarce data evaluating the association between the environment of birth, especially the season of birth and the month of birth, and non-communicable diseases.

It is now recognized that environmental factors in fetal life and in early infancy have impact on risks of diseases and mortality in adult life to a certain level $[2,3]$. Season and month of birth has in epidemiological studies been used as an indicator for prenatal and early postnatal exposures. Previous studies have reported the relationship between 
birth month, birth season and non-communicable diseases $[4,5]$. A retrospective population study systematically explored the relationship between birth month and lifetime disease risk found that 55 of 1,688 conditions were significantly related to birth month [4]. This report newly revealed associations between CVDs and birth month among human beings. Li et al. [5] used replication study confirmed the relationship between seasonal effects at birth and lifetime cardiovascular condition risk.

Global Burden of Disease Study 2017 showed that the number of global death registrations has steadily increased from 1950 to 2015, and it is estimated that 55 million deaths occurred in the world in 2017, of which 17.7 million were from CVD [6, 7]. CVD is the leading cause of both death and premature death in China [8,9], which accounts for $40 \%$ of deaths in the Chinese population [10]. Therefore, our study mainly focused on the relationship between season and month of birth, and all-cause and CVD death. In addition, there has been no evidence on these associations in China. Moreover, previous studies have shown conflicting results. Hence, the conclusion of the association in China may be different.

Therefore, the aim of our study was to explore the impact of birth season and birth month on the all-cause death and the CVD death using the longitudinal data from rural areas of China.

\section{Methods}

\section{Study population}

We conducted the present analysis using data from a large-scale epidemiological prospective study, the details of which have been described previously [11, 12]. Briefly, a multistage, random cluster sampling design was performed to select a representative sample of the rural population aged 35 years or older in Liaoning Province of China from 2004 to 2006. All study participants were invited to return for follow-ups: from January to July 2008; from July to December 2010; and from March to December 2017. Of the 45,925 participants at baseline, 3,883 subjects missing contact information or refusing to attend the follow-up, 42,042 participants were eligible to attend the follow-up (at least one follow-up rate 91.5\%). $32,568(70.9 \%)$ completed at least two follow-ups and $13,894(30.3 \%)$ participants completed all three followups. Of these population, subjects with missing key variables (demographics, lifestyle, CVD disease history) at baseline $(n=846)$ were excluded, leaving 41,196 participants for subsequent analysis. A total of 21,338 participants for the present analysis after we excluded 2,431 participants due to already suffering from CVD

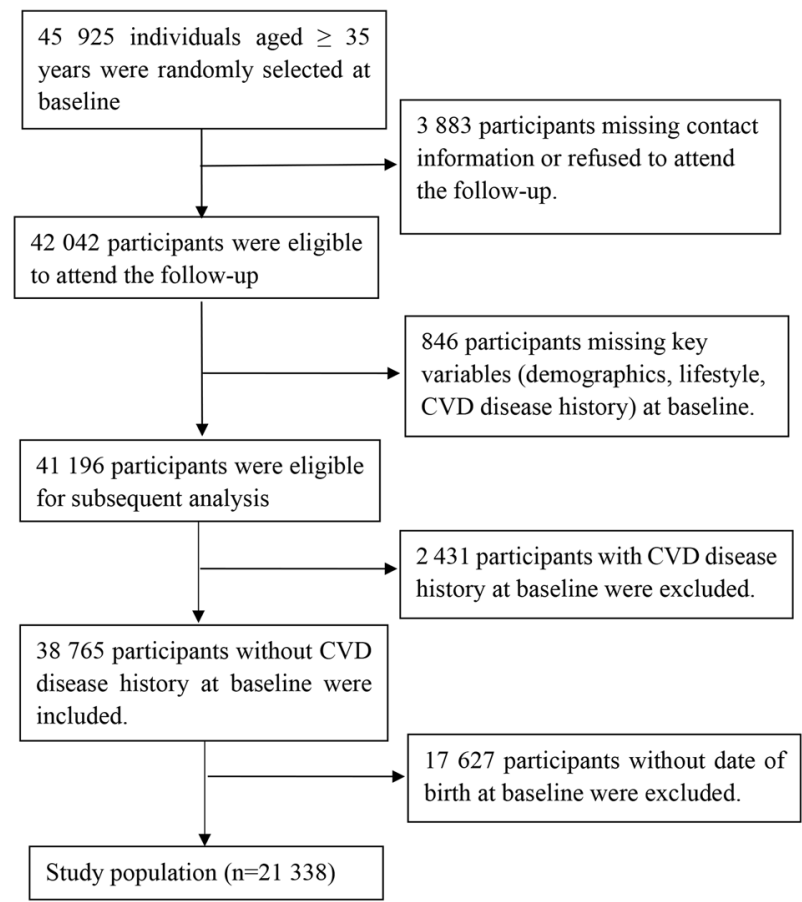

Fig. 1 Flow chart of participant recruitment and derivation of the population ued in the final analysis.

disease history at baseline and removed 17,627 participants owing to missing date of birth at baseline. Figure 1 shows detailed information about the sample size of participants and exclusion reasons in our study. The procedures followed were in accordance with the ethical standards of the responsible committee on human experimentation of the China Medical University, and written informed consents were obtained from all subjects or their proxies.

\section{Baseline examination and follow-ups}

Data on demographic variables (age, sex, and ethnicity), lifestyle factors (current smoking, current drinking status, and physical activity), CVD disease history (stroke and coronary heart disease included angina pectoris, arrhythmia, and myocardial infarction), and family history (hypertension, diabetes, or hyperlipidemia) were obtained by trained investigators through a standard questionnaire and measurements. Relevant definitions of the study have been described elsewhere [11, 12]. At each follow-up, we collected the information on clinical end points, adverse events, and concurrent medication use.

\section{Ascertainment of birth month and astronomical birth season}

Participants' identity card (ID) information was registered on the questionnaire in detail, we obtained the exact date of 
birth of the participant through their ID information. According to their identification number, month and season of birth were then ascertained. In our study, astronomical birth season was used, based on solstices and equinoxes as the bounds of the season categories. In consideration of minor variations on the timings of solstices and equinoxes in different years, four astronomical birth seasons were defined as the following standard: spring (March 21-June 20), summer (June 21-September 20), autumn (September 21-December 20), and winter (December 21-March 20) [13].

\section{Ascertainment of deaths}

Our results included all-cause mortality and CVD mortality. Deaths were confirmed through hospital records and direct contact with their families. Using the International Classification of Diseases, 9th Revision, Clinical Modification, deaths due to CVD were assigned a code from 400 through 444 including CHD, stroke, and others. We confirmed that death from CVD on the basis of autopsy reports, death certificates, medical record abstract, or information obtained from family members.

\section{Statistical analysis}

Continuous variables were presented as means and standard deviation (SD), while categorical variables were expressed as percentages. The rate of mortality was presented as the number of events per 1000 person-years. Age at death (mean $\pm \mathrm{SD}$ ) was calculated separately in 12 groups categorized by the month of birth.

Two models were applied in our statistical analysis. Model 1 was adjusted for the baseline age, Model 2 was adjusted for the baseline age, gender, ethnicity, BMI, hypertension, education level, physical activity, current drinking, current smoking, family history of hypertension, history of diabetes, history of hyperlipidemia. We explore the association between astronomical birth season, birth month and all-cause, CVD death, and non-CVD death, respectively, by using age and multivariable adjusted Cox proportional hazards models to calculate the HRs with 95\% CIs. The proportional hazard assumption in the Cox model was assessed with the Schoenfeld residual test and all proportionality assumptions were appropriate. Similarly, we stratified all participants by gender and examined the associations. We used the astronomical birth season and birth month as categorical variables, and we defined the autumn and the November as the reference, respectively. All analyses were performed by SPSS 22.0 (IBM Inc., Chicago, IL, USA). A 2sided $P$ value $<0.05$ was accepted as statistically significant.

\section{Results}

The study sample consisted of 21,338 participants, of whom four astronomical birth seasons had 4,754, 5,042, 5,785, and 5,757 participants, respectively. Table 1 presents participant characteristics stratified by astronomical birth season of spring, summer, autumn, winter. The mean (SD) age of the population was $50.1 \pm 10.6$ years, and 10,535 $(49.4 \%)$ of all participants were women. Participant characteristics stratified by birth month were displayed in the Supplementary file S1.

\section{Rate of mortality at the different groups of astronomical birth season and birth month}

During a median follow-up of 11.9 years, we observed that a total of 2,207 cases were all-cause death and 1,214 cases were attributed to CVD. Figure 2 shows the rate of all-cause death (A) and CVD death (B) grouping by astronomical birth season categories at follow-ups. The incidence rates of all-cause death in the four groups were 8.97, 8.80, 8.60, and 9.80 per 1000 person-years in total people, respectively. The event rates of CVD death were 5.20, 4.73, 4.65, and 5.35 per 1000 person-years in all participants, respectively. Season specific all-cause and CVD death rates in men and women are illustrated in Fig. 2.

Figure 3 shows the incidence rate of all-cause death (A) and CVD death (B) grouping by birth month categories. We can find the highest and lowest incidence rates, noted for all-cause mortality, were 10.27 and 8.29 per 1000 person-years for patients born in January and June, respectively. For CVD death, the highest and lowest event rates were 5.66 and 4.12 per 1000 person-years for patients born in April and June. Month specific all-cause and CVD death rates in men and women are illustrated in Fig. 3.

\section{Results of Cox proportional hazard ratios of all- cause, CVD death and non-CVD death across astronomical birth seasons and birth month}

Table 2 presents age and multivariable adjusted hazard ratios and $95 \%$ confidence intervals of all-cause and CVD death among study participants across astronomical birth seasons (all $P<0.05$ ). For all-cause death, compared with born in autumn, those born in spring and winter had a higher mortality in model 2 (HR of spring, 1.137, 95\% CI, 1.008-1.283; winter, 1.179, 1.054-1.320). For CVD mortality, people born in spring and winter with HRs (95\% CIs) of mortality in model 2 were $1.232(1.048,1.449)$ and 1.174 (1.007, 1.369), respectively.

The HRs and 95\% CIs of all-cause and CVD death among the study population across birth months are shown in Table 3 (all $P<0.05$ ). In model 2, we detected that 
Table 1 The baseline characteristics of the study population across astronomical birth seasons.

\begin{tabular}{|c|c|c|c|c|c|}
\hline Variables & $\begin{array}{l}\text { Spring } \\
(n=4754)\end{array}$ & $\begin{array}{l}\text { Summer } \\
(n=5042)\end{array}$ & $\begin{array}{l}\text { Autumn } \\
(n=5785)\end{array}$ & $\begin{array}{l}\text { Winter } \\
(n=5757)\end{array}$ & $P$ value \\
\hline Female, $n(\%)$ & $2339(49.2)$ & $2443(48.5)$ & $2870(49.6)$ & $2883(50.1)$ & 0.385 \\
\hline Age, (years) & $49.8 \pm 10.4$ & $49.9 \pm 10.5$ & $50.4 \pm 10.7$ & $50.4 \pm 10.8$ & 0.003 \\
\hline \multicolumn{6}{|l|}{ Ethnicity, $n(\%)$} \\
\hline Han & $3740(78.7)$ & $3971(78.8)$ & 4504 (77.9) & $4527(78.6)$ & \multirow[t]{3}{*}{0.827} \\
\hline Mongolia & $951(20.0)$ & $1009(20.0)$ & $1212(21.0)$ & $1153(20.0)$ & \\
\hline Other & $63(1.3)$ & $62(1.2)$ & $69(1.2)$ & $77(1.3)$ & \\
\hline BMI, $\left(\mathrm{kg} / \mathrm{m}^{2}\right)$ & $23.20 \pm 2.79$ & $23.13 \pm 2.64$ & $23.10 \pm 2.73$ & $23.26 \pm 2.72$ & 0.006 \\
\hline \multicolumn{6}{|l|}{ Education level, $n(\%)$} \\
\hline Never or $<5$ years & $1999(42.1)$ & $2144(42.5)$ & $2560(44.3)$ & $2591(45.0)$ & \multirow[t]{3}{*}{0.024} \\
\hline Primary school & $2518(53.0)$ & $2619(51.9)$ & $2923(50.5)$ & $2876(50.0)$ & \\
\hline $\begin{array}{l}\text { Tertiary high school or } \\
\text { higher education }\end{array}$ & $237(5.0)$ & $279(5.5)$ & $302(5.2)$ & $290(5.0)$ & \\
\hline \multicolumn{6}{|l|}{ Physical activities, $n(\%)$} \\
\hline Low & $1056(22.2)$ & $1161(23.0)$ & $1327(22.9)$ & $1415(24.6)$ & \multirow[t]{3}{*}{0.055} \\
\hline Moderate & $2237(47.1)$ & $2289(45.4)$ & $2692(46.5)$ & $2641(45.9)$ & \\
\hline High & $1461(30.7)$ & $1592(31.6)$ & $1766(30.5)$ & $1701(29.6)$ & \\
\hline Current drinking, $n(\%)$ & $1557(32.8)$ & $1640(32.5)$ & $1870(32.3)$ & $1832(31.8)$ & 0.764 \\
\hline Current smoking, $n(\%)$ & $2003(42.1)$ & $2158(42.8)$ & $2519(43.5)$ & $2373(41.2)$ & 0.077 \\
\hline $\begin{array}{l}\text { Family history of } \\
\text { hypertension, n (\%) }\end{array}$ & $595(12.5)$ & $656(13.0)$ & $744(12.9)$ & $756(13.1)$ & 0.810 \\
\hline History of diabetes, $n(\%)$ & $14(0.3)$ & $20(0.4)$ & $16(0.3)$ & $25(0.4)$ & 0.426 \\
\hline $\begin{array}{l}\text { History of hyperlipidemia, } \\
n(\%)\end{array}$ & $122(2.6)$ & $141(2.8)$ & $132(2.3)$ & $184(3.2)$ & 0.021 \\
\hline
\end{tabular}

Variables are shown as mean $\pm \mathrm{SD}$ or frequencies.

$B M I$ body mass index

Astronomical birth seasons created following solstices and equinoxes (spring: March 21 to June 20, summer: June 21 to September 20, autumn: September 21 to December 20, and winter: December 21 to March 20). compared with born in November, those born in January, March, May and August had a higher mortality for all-cause death (HR for January, 1.249, 95\% CI, 1.027-1.518; March, 1.234, 1.008-1.512; May, 1.276, 1.037-1.571; August, 1.232, 1.003-1.513). For CVD mortality, March with HR $(95 \% \mathrm{CI})$ of mortality in model 2 were 1.343 $(1.030,1.750)$. No statistically significant differences were found in other groups. For non-CVD death, compared with born in November, those born in January and December had a higher risk (HR for January, 1.380, 95\% CI, 1.031-1.849; December, 1.376, 1.027-1.844 in model 2). The results were shown in Supplementary file S2.

We can detect from Tables 4 and 5 that the relationship between astronomical birth season, birth month, and the rate of all-cause mortality and CVD mortality by gender (all $P<$ 0.05 ). Of these results, for all-cause death, compared with born in autumn, those born in winter had a higher mortality in model 2 (HR of winter, 1.155, 95\% CI, 1.003-1.330) in men. For CVD mortality, people born in spring with HRs (95\% CIs) were $1.274(1.039,1.561)$ in men. In addition, we detected that, compared with born in November, women born in February, May and August had a higher mortality for all-cause death (HR for February, 1.399, 1.003-1.951; May, 1.473, 1.049-2.069; August, 1.408, (1.004-1.972) in model 2. For CVD death, participants only born in March had a higher rate in model 2 (HR, 1.413, 95\% CI, 1.012-1.972) in men.

\section{Discussion}

To our knowledge, none of previous studies has been able to explore whether astronomical season and month of birth were significant predictors of mortality in China. Based on longitudinal population data from China, we found that astronomical season and month of birth are related to allcause and CVD death. Our data showed that the highest allcause mortality was observed in people born in the winter/ spring (January-May), peaking in January, and the lowest mortality was observed among those individuals born in June. Similarly, subjects born in the winter/spring (March-May), peaking in April, had the highest CVD mortality risk, and the lowest mortality was detected in those born in June. More interesting for us, the results of 

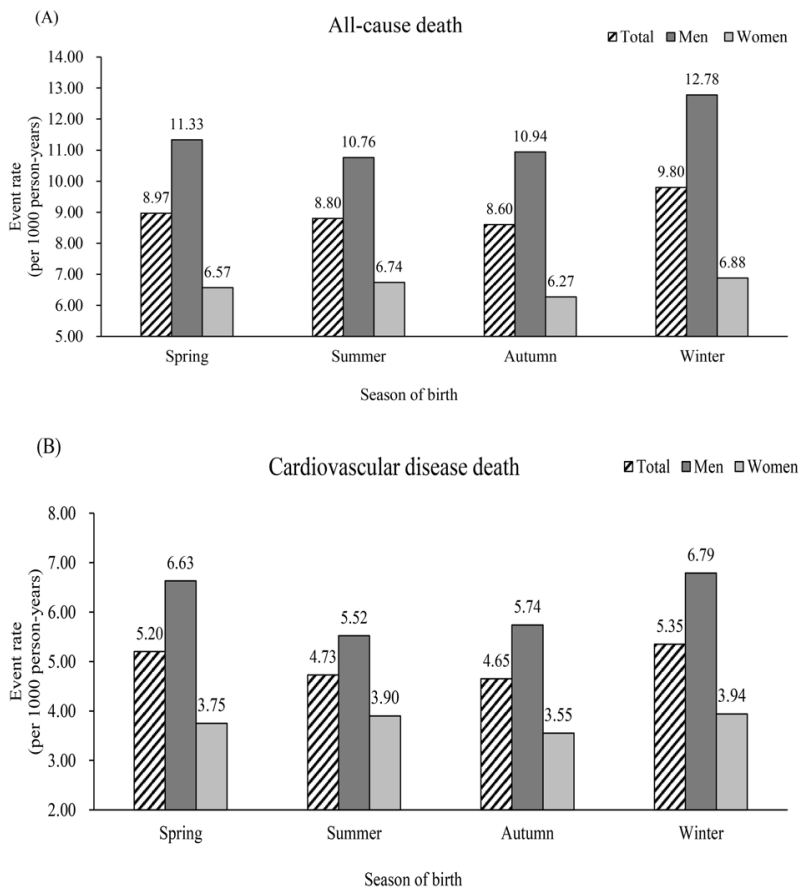

Fig. 2 The event rates of all-cause death and cardiovascular disease death by seasons. Incident (A) All-cause mortality, (B) CVD mortality at the different seasons. our study revealed that subjects born in August was a significant predictor of all-cause death in all population especially women.

Previous studies have demonstrated the relationship in other countries. A study compared centenarians to their shorter-lived siblings and spouses using a large set of computerized family histories in USA [14]. The authors found that persons born in the fall months are more represented among centenarians compared to the general population. In addition, they found that individuals born in September-November have higher likelihood of becoming centenarians compared to March-born individuals. A nationwide Swedish cohort study showed that the highest mortality in those born in the spring/summer [15]. Alexander et al. [16] detected individuals born in May through July had the lowest age at death in a German subpopulation. Gabriele et al. [17] analyzed Danish and Austrian participants and concluded that born in autumn (October-December) live longer than those born in spring (April-June). A prospective study in US also reached the same conclusion [18]. These findings have similar results, from which we concluded that there was a general increase in the all-cause death among people born in spring/summer (March-July). The same is true for cardiovascular death outcomes. The Nurses' Health

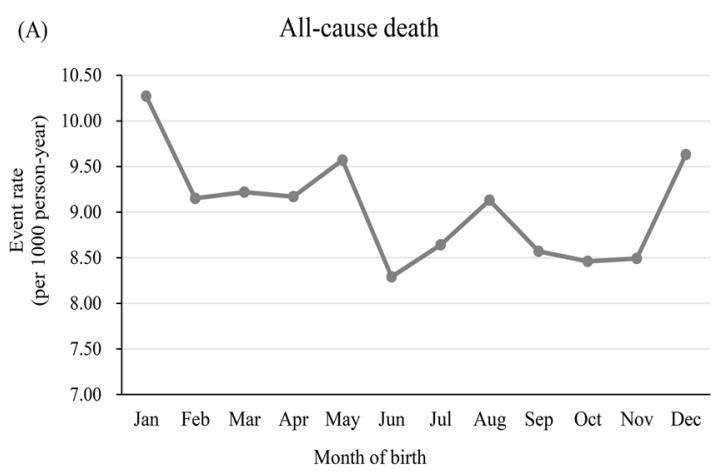

(C)
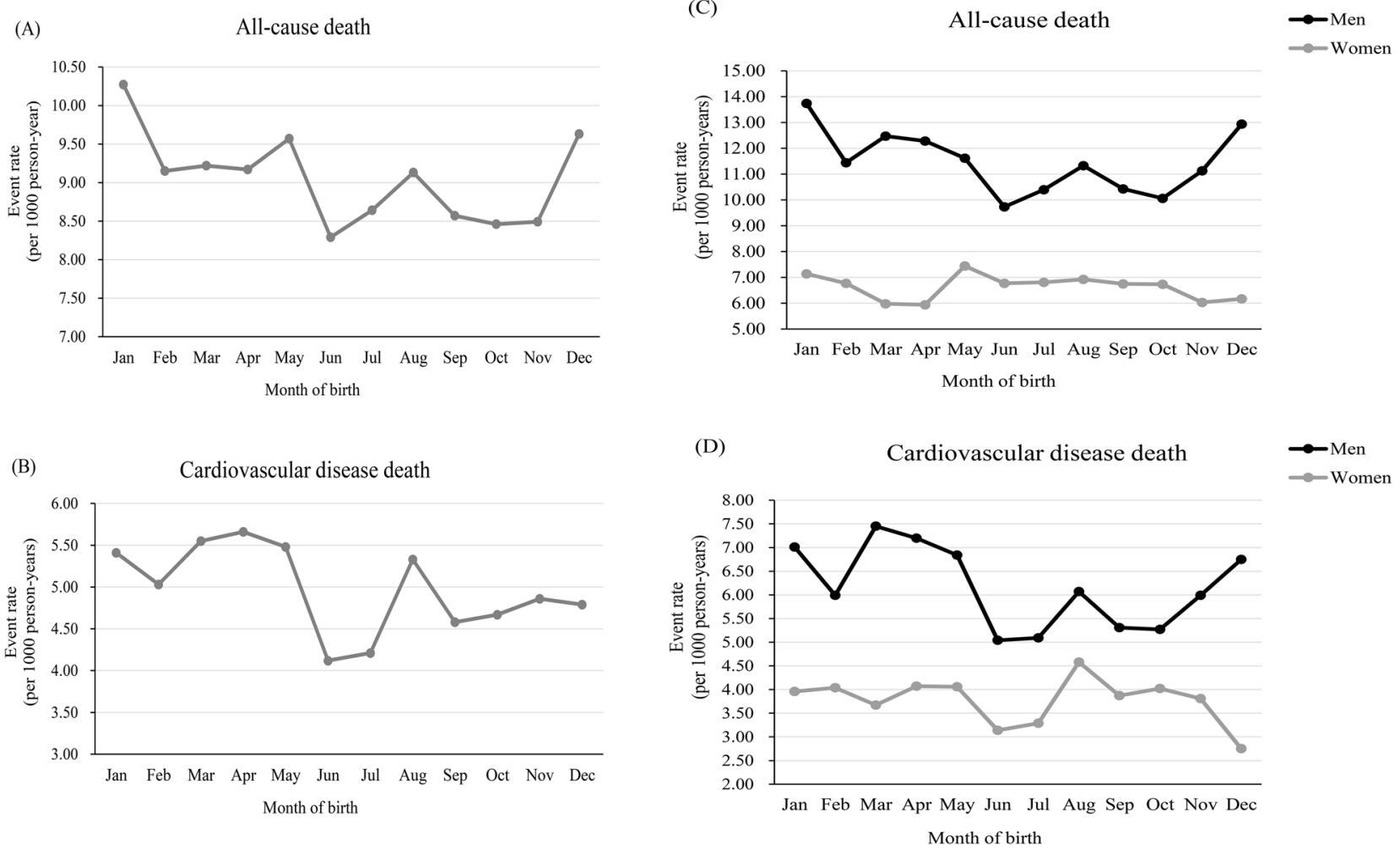

Fig. 3 The event rates of all-cause death and cardiovascular disease death by months. Incident (A) All-cause mortality, (B) CVD mortality at the different months. Incident (C) All-cause mortality, (D) CVD mortality at the different months by sex. 
Table 2 Age adjusted and multivariable adjusted Cox proportional hazard ratios of all-cause death and cardiovascular disease death across astronomical birth seasons.

\begin{tabular}{|c|c|c|c|c|}
\hline \multirow[t]{3}{*}{ Astronomical birth seasons } & \multicolumn{2}{|l|}{ All-cause death } & \multicolumn{2}{|c|}{ Cardiovascular disease death } \\
\hline & Model 1 & Model 2 & Model 1 & Model 2 \\
\hline & Hazard ratio $(95 \% \mathrm{CI})$ & Hazard ratio $(95 \% \mathrm{CI})$ & Hazard ratio $(95 \% \mathrm{CI})$ & Hazard ratio $(95 \% \mathrm{CI})$ \\
\hline Spring & $1.137(1.008,1.283)$ & $1.134(1.005,1.280)$ & $1.239(1.054,1.456)$ & $1.232(1.048,1.449)$ \\
\hline Summer & $1.104(0.979,1.244)$ & $1.072(0.951,1.209)$ & $1.112(0.945,1.309)$ & $1.069(0.908,1.284)$ \\
\hline Autumn & 1.000 (ref) & 1.000 (ref) & $1.000(\mathrm{ref})$ & 1.000 (ref) \\
\hline Winter & $1.179(1.054,1.320)$ & $1.162(1.038,1.301)$ & $1.198(1.028,1.397)$ & $1.174(1.007,1.369)$ \\
\hline
\end{tabular}

Model 1 was adjusted for age.

Model 2 was adjusted for age, gender, ethnicity, BMI, hypertension, education level, physical activity, current drinking, current smoking, family history of hypertension, history of diabetes, history of hyperlipidemia.

Astronomical birth seasons defined on the basis of solstices and equinoxes as the bounds of the season categories rather than as the midpoints: winter (December 21 to March 20), spring (March 21 to June 20), summer (June 21 to September 20), and autumn (September 21 to December 20).

Table 3 Age adjusted and multivariable adjusted Cox proportional hazard ratios of allcause death and cardiovascular disease death across birth months.

\begin{tabular}{|c|c|c|c|c|}
\hline \multirow[t]{3}{*}{ Birth months } & \multicolumn{2}{|l|}{ All-cause death } & \multicolumn{2}{|c|}{ Cardiovascular disease death } \\
\hline & Model 1 & Model 2 & Model 1 & Model 2 \\
\hline & Hazard ratio $(95 \% \mathrm{CI})$ & Hazard ratio $(95 \% \mathrm{CI})$ & Hazard ratio $(95 \% \mathrm{CI})$ & Hazard ratio $(95 \% \mathrm{CI}$ \\
\hline January & $1.280(1.053,1.556)$ & $1.249(1.027,1.518)$ & $1.195(0.919,1.555)$ & $1.155(0.887,1.502)$ \\
\hline February & $1.233(1.009,1.506)$ & $1.165(0.953,1.423)$ & $1.212(0.927,1.584)$ & $1.127(0.862,1.474)$ \\
\hline March & $1.287(1.051,1.576)$ & $1.234(1.008,1.512)$ & $1.396(1.071,1.818)$ & $1.343(1.030,1.750)$ \\
\hline April & $1.222(0.992,1.505)$ & $1.194(0.969,1.470)$ & $1.344(1.026,1.761)$ & $1.306(0.997,1.711)$ \\
\hline May & $1.321(1.074,1.626)$ & $1.276(1.037,1.571)$ & $1.361(1.034,1.790)$ & $1.307(0.994,1.720)$ \\
\hline June & $1.161(0.932,1.446)$ & $1.110(0.891,1.383)$ & $1.040(0.769,1.406)$ & $0.977(0.722,1.322)$ \\
\hline July & $1.185(0.955,1.469)$ & $1.115(0.899,1.384)$ & $1.037(0.770,1.397)$ & $0.953(0.707,1.285)$ \\
\hline August & $1.290(1.050,1.584)$ & $1.232(1.003,1.513)$ & $1.370(1.045,1.795)$ & $1.293(0.986,1.695)$ \\
\hline September & $1.085(0.886,1.329)$ & $1.045(0.853,1.280)$ & $1.024(0.780,1.345)$ & $0.980(0.746,1.287)$ \\
\hline October & $1.125(0.921,1.374)$ & $1.055(0.864,1.289)$ & $1.116(0.855,1.457)$ & $1.034(0.792,1.350)$ \\
\hline November & 1.000 (ref) & 1.000 (ref) & 1.000 (ref) & 1.000 (ref) \\
\hline December & $1.240(1.017,1.512)$ & $1.175(0.963,1.433)$ & $1.104(0.842,1.449)$ & $1.025(0.781,1.344)$ \\
\hline
\end{tabular}

Model 1 was adjusted for age.

Model 2 was adjusted for age, gender, ethnicity, BMI, hypertension, education level, physical activity, current drinking, current smoking, family history of hypertension, history of diabetes, history of hyperlipidemia.
Study cohort [13] observed that women born in the spring and summer (especially March through July) had an increased CVD mortality. A large longitudinal cohort study in Sweden concluded that the highest CVD mortality happened to those born between March and April. A Lithuania study, although distinctively smaller than the other studies and ours, indicated similar findings [19].

We had relatively consistently described participants born in spring (especially from March to May) have the highest mortality of all-cause and CVD death, and people born in autumn (especially in November) have the lowest mortality. However, contrary to the conclusion that summer (especially July) increased mortality in other countries, winter was the season with the highest mortality in our study in China, and for all-cause death, being born in January was associated with death and was the highest rate of all months, which have not been reported previously in other research settings. It was uncertain what explain the current results although there were several factors which might be important. Firstly, several researches reported that winter was a high-risk time, perinatal and neonatal mortality was influenced by extreme cold in winter [20, 21], and January is the coldest month of winter in China. Secondly, many studies have demonstrated a link between early life nutrition and cardiovascular health and mortality in adulthood [22, 23]. In China, autumn is the harvest season for agricultural and sideline products, fruit and vegetable throughout the year. In the middle of the twentieth century, 
Table 4 Age adjusted and multivariable adjusted Cox proportional hazard ratios of all-cause death and cardiovascular disease death across astronomical birth seasons by sex.

\begin{tabular}{|c|c|c|c|c|c|}
\hline \multirow[t]{3}{*}{ Model } & \multirow[t]{3}{*}{ Astronomical birth seasons } & \multicolumn{2}{|l|}{ All-cause death } & \multicolumn{2}{|c|}{ Cardiovascular disease death } \\
\hline & & Men & Women & Men & Women \\
\hline & & Hazard ratio $(95 \% \mathrm{CI})$ & Hazard ratio $(95 \% \mathrm{CI})$ & Hazard ratio $(95 \% \mathrm{CI})$ & Hazard ratio $(95 \% \mathrm{CI})$ \\
\hline \multirow[t]{4}{*}{ Model 1} & Spring & $1.126(0.968,1.311)$ & $1.149(0.940,1.404)$ & $1.276(1.041,1.564)$ & $1.168(0.896,1.524)$ \\
\hline & Summer & $1.037(0.892,1.206)$ & $1.197(0.983,1.457)$ & $1.023(0.829,1.261)$ & $1.245(0.960,1.615)$ \\
\hline & Autumn & 1.000 (ref) & 1.000 (ref) & 1.000 (ref) & 1.000 (ref) \\
\hline & Winter & $1.160(1.007,1.336)$ & $1.204(0.997,1.453)$ & $1.171(0.964,1.422)$ & $1.232(0.959,1.581)$ \\
\hline \multirow[t]{4}{*}{ Model 2} & Spring & $1.126(0.967,1.310)$ & $1.147(0.939,1.402)$ & $1.274(1.039,1.561)$ & $1.165(0.893,1.521)$ \\
\hline & Summer & $1.018(0.875,1.184)$ & $1.171(0.962,1.427)$ & $0.993(0.805,1.225)$ & $1.202(0.926,1.561)$ \\
\hline & Autumn & 1.000 (ref) & 1.000 (ref) & 1.000 (ref) & 1.000 (ref) \\
\hline & Winter & $1.155(1.003,1.330)$ & $1.194(0.989,1.442)$ & $1.168(0.962,1.419)$ & $1.207(0.940,1.551)$ \\
\hline
\end{tabular}

Model 1 was adjusted for age.

Model 2 was adjusted for age, ethnicity, BMI, hypertension, education level, physical activity, current drinking, current smoking, family history of hypertension, history of diabetes, history of hyperlipidemia.

Astronomical birth seasons defined on the basis of solstices and equinoxes as the bounds of the season categories rather than as the midpoints: winter (December 21 to March 20), spring (March 21 to June 20), summer (June 21 to September 20), and autumn (September 21 to December 20).

food supply, especially fruit and vegetables, was much dependent on season. Compared to mothers of infants born at autumn, mothers of infants born in winter may have had a fewer favorable nutritional status [24]. Thirdly, according to Chinese national conditions, January, the last month of the Chinese lunar calendar, the tail of year, is about to reach the Spring Festival. People prepare for the upcoming Spring Festival, and all tasks that were unfinished during the year were asked to complete in this month. People become extremely busy, and babies who are about to be born or who are just born may receive less care than those born in other months. What's more, there is evidence that individuals who were born in the later period of different time indexes may have had increased stressors through their life course [25]. Those born in January were the youngest among their peers of the same grade in school. Previous study detected that those who were older than their peers in the same school year obtained better academic outcomes and higher earnings in adulthood [25]. Those born in January may experience psychological stress that can affect their health by failing to meet the expectations of their families or even society.

Even more surprising to us, being born in August was associated with a higher likelihood of dying of all-cause mortality among females in China. August in China is the hottest month of summer. Previous studies found that fetuses that were exposed to half a month of temperature $\geq 30{ }^{\circ} \mathrm{C}$ between 2 and 8 weeks post-conception had 1.06 times the risk of critical CHD defects [26]. Other literature also introduced the direct impact of increased temperatures and heat-waves on health [27]. The sex difference in the association between people born in August and mortality might have been due to women are weaker and more vulnerable to heat than men.

Season and month of birth represent proxies for various complex environmental and other factors in prenatal and early postnatal life. Socioeconomic status, parents' education level, and family environment are also important factors [13]. Maternal vitamin D status during pregnancy has been highlighted as a suggestive early life nutritional factor of adult cardiovascular risk or other diseases [28]. Per Tornhammar et al. [29] reported that subjects born after the winter had lower neonatal $25(\mathrm{OH}) \mathrm{D}_{3}$ concentrations than did those born after the summer. This may be due to higher ultraviolet light (UVB) in summer than in winter, skin exposure to UVB is the main determinant for vitamin D-levels in humans.

\section{Strengths and limitations}

The primary strength of the present study was that we had a large sample in long period of follow-up and more examinations than other studies, so that we had the ability to analyze the relationship between birth season, birth month and all-cause and CVD death. Moreover, it was the first study in China to examine the relationship between them. And we were the first to report that January was the month with the highest all-cause mortality in China.

However, some limitations also need to be considered in this study. Firstly, of the 42,042 participants, 17,267 were excluded from our study without investigating their date of 
Table 5 Age adjusted and multivariable adjusted Cox proportional hazard ratios of all-cause death and cardiovascular disease death across birth months by sex.

\begin{tabular}{|c|c|c|c|c|c|}
\hline \multirow[t]{3}{*}{ Model } & \multirow[t]{3}{*}{ Astronomical birth seasons } & \multicolumn{2}{|l|}{ All-cause death } & \multicolumn{2}{|c|}{ Cardiovascular disease death } \\
\hline & & Men & Women & Men & Women \\
\hline & & Hazard ratio $(95 \% \mathrm{CI})$ & Hazard ratio $(95 \% \mathrm{CI})$ & Hazard ratio $(95 \% \mathrm{CI})$ & Hazard ratio $(95 \% \mathrm{CI})$ \\
\hline \multirow[t]{12}{*}{ Model 1} & January & $1.242(0.972,1.587)$ & $1.329(0.963,1.835)$ & $1.188(0.847,1.666)$ & $1.189(0.783,1.807)$ \\
\hline & February & $1.086(0.845,1.397)$ & $1.440(1.033,2.007)$ & $1.058(0.749,1.495)$ & $1.422(0.931,2.172)$ \\
\hline & March & $1.257(0.979,1.615)$ & $1.269(0.898,1.794)$ & $1.430(1.025,1.995)$ & $1.272(0.819,1.975)$ \\
\hline & April & $1.244(0.962,1.608)$ & $1.124(0.786,1.607)$ & $1.377(0.977,1.940)$ & $1.242(0.800,1.928)$ \\
\hline & May & $1.176(0.905,1.529)$ & $1.507(1.074,2.114)$ & $1.326(0.935,1.880)$ & $1.328(0.853,2.068)$ \\
\hline & June & $1.018(0.769,1.346)$ & $1.355(0.951,1.930)$ & $1.017(0.692,1.496)$ & $1.014(0.623,1.650)$ \\
\hline & July & $1.046(0.796,1.374)$ & $1.398(0.985,1.986)$ & $0.965(0.659,1.416)$ & $1.123(0.697,1.809)$ \\
\hline & August & $1.159(0.894,1.502)$ & $1.468(1.049,2.056)$ & $1.194(0.838,1.701)$ & $1.610(1.059,2.446)$ \\
\hline & September & $0.960(0.742,1.242)$ & $1.263(0.910,1.754)$ & $0.914(0.640,1.306)$ & $1.160(0.760,1.770)$ \\
\hline & October & $0.968(0.752,1.246)$ & $1.350(0.974,1.871)$ & $0.960(0.679,1.357)$ & $1.322(0.872,2.005)$ \\
\hline & November & 1.000 (ref) & 1.000 (ref) & 1.000 (ref) & 1.000 (ref) \\
\hline & December & $1.215(0.951,1.552)$ & $1.179(0.839,1.656)$ & $1.199(0.857,1.678)$ & $0.852(0.532,1.365)$ \\
\hline \multirow[t]{12}{*}{ Model 2} & January & $1.224(0.958,1.564)$ & $1.306(0.946,1.805)$ & $1.163(0.829,1.632)$ & $1.151(0.757,1.751)$ \\
\hline & February & $1.066(0.828,1.371)$ & $1.399(1.003,1.951)$ & $1.027(0.727,1.450)$ & $1.345(0.879,2.056)$ \\
\hline & March & $1.230(0.957,1.580)$ & $1.239(0.876,1.752)$ & $1.413(1.012,1.972)$ & $1.197(0.770,1.860)$ \\
\hline & April & $1.230(0.951,1.591)$ & $1.113(0.778,1.591)$ & $1.354(0.961,1.909)$ & $1.210(0.779,1.880)$ \\
\hline & May & $1.166(0.897,1.517)$ & $1.473(1.049,2.069)$ & $1.303(0.918,1.849)$ & $1.279(0.820,1.995)$ \\
\hline & June & $0.989(0.748,1.309)$ & $1.303(0.914,1.858)$ & $0.956(0.650,1.407)$ & $0.969(0.594,1.580)$ \\
\hline & July & $1.000(0.761,1.315)$ & $1.339(0.942,1.903)$ & $0.901(0.614,1.322)$ & $1.073(0.665,1.732)$ \\
\hline & August & $1.141(0.880,1.479)$ & $1.408(1.004,1.972)$ & $1.163(0.816,1.658)$ & $1.490(0.978,2.268)$ \\
\hline & September & $0.928(0.716,1.201)$ & $1.253(0.902,1.742)$ & $0.869(0.607,1.242)$ & $1.116(0.730,1.706)$ \\
\hline & October & $0.934(0.725,1.203)$ & $1.316(0.949,1.825)$ & $0.908(0.641,1.285)$ & $1.268(0.835,1.925)$ \\
\hline & November & 1.000 (ref) & 1.000 (ref) & 1.000 (ref) & 1.000 (ref) \\
\hline & December & $1.182(0.925,1.510)$ & $1.130(0.804,1.589)$ & $1.141(0.815,1.598)$ & $0.785(0.489,1.259)$ \\
\hline
\end{tabular}

Model 1 was adjusted for age.

Model 2 was adjusted for age, ethnicity, BMI, hypertension, education level, physical activity, current drinking, current smoking, family history of hypertension, history of diabetes, history of hyperlipidemia.

birth, which resulted in a reduction in our sample size. Secondly, the findings should be interpreted with caution because the significant association of birth season and birth month might be attenuated by unadjusted residual confounding, such as participants' economic status, family environment, parental education level, and maternal nutrition status during pregnancy. Further studies are required to explore the field with adjusting these factors. Thirdly, nearbirth familial and socioeconomic factors could influence the timing of conception and thus birth, later life socioeconomic and psychiatry factors might also be associated with overall and cardiovascular mortality in adulthood. However, we are short of relevant data. In addition, we also lack important information about birth, such as birth weight, diseases, limited our ability to capture the complexity of the birth situation comprehensively. Finally, we only observed a limited sample consisting of rural Chinese people which may affect the generalizability of our results to other area populations.

\section{Conclusion}

Although more researches are needed to determine what underlies this result, this prospective cohort study suggested that in China people born in winter/spring have increased all-cause and CVD mortality compared with those born in the autumn. The results of this study showed that, first, people born in winter or spring are suggested to pay more attention to strengthen the prevention of cardiovascular disease. Second, women born in August should be more aware of their health condition. Last, for the fetuses who will be born in winter or spring, their parents provide a more comfortable birth environment for their babies. 


\section{Summary}

\section{What is already known about this subject?}

- It is now recognized that environmental factors in fetal life and in early infancy have impact on risks of diseases and mortality in adult life to a certain level.

- Season and month of birth has in epidemiological studies been used as an indicator for prenatal and early postnatal exposures.

- Previous studies have similar results that there was a general increase in the all-cause and cardiovascular disease death among people born in spring/summer (March-July) in other countries.

\section{What does this study add?}

- In China the highest all-cause mortality was observed in people born in the winter/spring (January-May), peaking in January, and the lowest mortality was observed among those individuals born in June. Similarly, subjects born in the winter/spring (March-May), peaking in April, had the highest CVD mortality risk, and the lowest mortality was detected in those born in June.

- The results of our study revealed that subjects born in August was a significant predictor of all-cause death in all population especially women.

Acknowledgements All of the investigators and staff members were gratefully acknowledged. Thanks for all the enthusiastic participants.

Author contributions ZG: Conceptualization; Writing-original draft. SL: Methodology; Validation. YD: Formal analysis. RG: Investigation. YW: Data curation. ZS: Supervision; Resources. LX: Investigation; Resources. YS: Project administration. LZ: Conceptualization; Writing—review and editing.

Funding This research was supported by funds from National Key R\&D Program of China [Grant\#2018YFC1311600], Xingliao Talents Program of Liaoning Province [Grant \#XLYC1808036], National Nature Science Foundation of China [No. 81773510], National Key R\&D Program of China [Grant \#2017YFC1307600], and 345 Talent Project of Shengjing Hospital.

\section{Compliance with ethical standards}

Conflict of interest The authors declare that they have no conflict of interest.

Publisher's note Springer Nature remains neutral with regard to jurisdictional claims in published maps and institutional affiliations.

\section{References}

1. Zhu N, Zhang D, Wang W, Li X, Yang B, Song J, et al. A novel coronavirus from patients with pneumonia in China, 2019. N Engl J Med. 2020;382:727-33.

2. Gluckman PD, Hanson MA. Living with the past: evolution, development, and patterns of disease. Science. 2004;305:1733-6.

3. Rinaudo P, Wang E. Fetal programming and metabolic syndrome. Annu Rev Physiol. 2012;74:107-30.

4. Boland MR, Shahn Z, Madigan D, Hripcsak G, Tatonetti NP. Birth month affects lifetime disease risk: a phenome-wide method. J Am Med Inform Assoc. 2015;22:1042-53.

5. Li L, Boland MR, Miotto R, Tatonetti NP, Dudley JT. Replicating cardiovascular condition-birth month associations. Sci Rep. 2016;6:33166

6. GBD 2017 Causes of Death Collaborators. Global, regional, and national age-sex-specific mortality for 282 causes of death in 195 countries and territories, 1980-2017: a systematic analysis for the Global Burden of Disease Study 2017. Lancet. 2018;392: 1736-88.

7. GBD 2017 Causes of Death Collaborators. Global, regional, and national age-sex-specific mortality and life expectancy, 1950-2017: a systematic analysis for the Global Burden of Disease Study 2017. Lancet. 2018;392:1684-735.

8. Zhou M, Wang H, Zhu J, Chen W, Wang L, Liu S, et al. Causespecific mortality for 240 causes in China during 1990-2013: a systematic subnational analysis for the Global Burden of Disease Study 2013. Lancet. 2016;387:251-72.

9. Yang G, Wang Y, Zeng Y, Gao GF, Liang X, Zhou M, et al. Rapid health transition in China, 1990-2010: findings from the Global Burden of Disease Study 2010. Lancet. 2013;381: 1987-2015.

10. Zhao D, Liu J, Wang M, Zhang X, Zhou M. Epidemiology of cardiovascular disease in China: current features and implications. Nat Rev Cardiol. 2019;16:203-12.

11. Zheng L, Sun Z, Zhang X, Li J, Hu D, Chen J, et al. Predictive value for the rural Chinese population of the Framingham hypertension risk model: results from Liaoning Province. Am J Hypertens. 2014;27:409-14.

12. Zheng L, Zhang Z, Sun Z, Li J, Zhang X, Xu C, et al. The association between body mass index and incident hypertension in rural women in China. Eur J Clin Nutr. 2010;64:769-75.

13. Zhang Y, Devore EE, Strohmaier S, Grodstein F, Schernhammer ES. Birth month, birth season, and overall and cardiovascular disease mortality in US women: prospective cohort study. BMJ. 2019;367:16058.

14. Gavrilov LA, Gavrilova NS. Season of birth and exceptional longevity: comparative study of american centenarians, their siblings, and spouses. J Aging Res. 2011;2011:104616.

15. Ueda P, Bonamy AE, Granath F, Cnattingius S. Month of birth and mortality in Sweden: a nation-wide population-based cohort study. PLoS One. 2013;8:e56425.

16. Lerchl A. Month of birth and life expectancy: role of gender and age in a comparative approach. Naturwissenschaften. 2004;91:422-5.

17. Doblhammer G, Vaupel JW. Lifespan depends on month of birth. Proc Natl Acad Sci USA. 2001;98:2934-9.

18. Sohn K. The influence of birth season on mortality in the United States. Am J Hum Biol. 2016;28:662-70.

19. Stoupel E, Tamoshiunas A, Radishauskas R, Abramson E, Bernotiene $\mathrm{G}$, Bacevichiene $\mathrm{M}$. Birth month and longevity: birth month of victims of sudden $(\mathrm{SCD},</=1 \mathrm{~h}$ ) and rapid (RCD, $</=24$ h) cardiac deaths. J Basic Clin Physiol Pharm. 2013;24:235-9. 
20. Schumann B, Haggstrom Lundevaller E, Karlsson L. Weather extremes and perinatal mortality - Seasonal and ethnic differences in northern Sweden, 1800-1895. PLoS One. 2019;14:e0223538.

21. Karlsson L, Lundevaller E, Schumann B. The association between cold extremes and neonatal mortality in Swedish Sapmi from 1800 to 1895 . Glob Health Action. 2019;12:1623609.

22. Painter RC, Roseboom TJ, Bleker OP. Prenatal exposure to the Dutch famine and disease in later life: an overview. Reprod Toxicol. 2005;20:345-52.

23. Marciniak A, Patro-Małysza J, Kimber-Trojnar Z, Marciniak B, Oleszczuk J, Leszczyńska-Gorzelak B. Fetal programming of the metabolic syndrome. Taiwan J Obstet Gynecol. 2017;56:133-8.

24. Villar J, Belizan JM. The timing factor in the pathophysiology of the intrauterine growth retardation syndrome. Obstet Gynecol Surv. 1982;37:499-506.

25. Inoue Y, Stickley A, Yazawa A, Fujiwara T, Konndo K, Kondo $\mathrm{N}$. Month of birth is associated with mortality among older people in Japan: findings from the JAGES cohort. Chronobiol Int. 2016;33:441-7.

26. Auger N, Fraser WD, Sauve R, Bilodeau-Bertrand M, Kosatsky T. Risk of congenital heart defects after ambient heat exposure early in pregnancy. Environ Health Perspect. 2017; 125:8-14.

27. Arbuthnott KG, Hajat $\mathrm{S}$. The health effects of hotter summers and heat waves in the population of the United Kingdom: a review of the evidence. Environ Health. 2017;16:119.

28. Pasco JA, Wark JD, Carlin JB, Ponsonby AL, Vuillermin PJ, Morley R. Maternal vitamin D in pregnancy may influence not only offspring bone mass but other aspects of musculoskeletal health and adiposity. Med Hypotheses. 2008;71:266-9.

29. Tornhammar P, Ueda P, Hult M, Simila H, Eyles D, Norman M. Season of birth, neonatal vitamin D status, and cardiovascular disease risk at 35 years of age: a cohort study from Sweden. Am J Clin Nutr. 2014;99:472-8. 